\title{
Impact of Exclusive English Language Use in Physiology Lecture on Student's Physiology Learning in Bangladesh
}

\author{
Mohammad Uzire Azam Khan', Mohammad Mohaimenul Abedin²
}

\begin{abstract}
Background: Medical students of Bangladesh have to encounter English as learning media. But teachers often do not use English exclusively in their lectures thinking that students may not understand English clearly. Objective: To assess the impact of exclusive use of English language in physiology lectures on student's learning. Method: This comparative study was conducted in the Department of Physiology, Abdul Malek Ukil Medical College, Noakhali, Bangladesh during January - November, 2013. One hundred and sixteen first year MBBS students of two sessions of a government medical college were enrolled for the study by purposive sampling. Exclusive English was used in physiology lectures of $1^{\text {st }}$ term course for the students of 2012-2013 session (group EE) and mixed Bengali and English was used to teach the students of 2011-2012 session (group BE). First term examination results were compared by Student's ' $t$ ' test and Chi-square test as applicable. Result: The students of EE obtained significantly higher mean marks both in written $(p<0.001)$ and oral $(p<0.001)$ examinations than those of group BE. However there was no significant difference between groups in pass rate $(\mathrm{p}>0.05))$. Conclusion: The students who attended the lectures with exclusive English obtained better marks in individual component of assessment than the students who attended the lectures with mixed Bengali and English. However, English language use in teaching showed no effect on the pass rate.
\end{abstract}

Key words: Exclusive English, learning Physiology

J Bangladesh Soc Physiol. 2017, June; 12(1): 28-32 For Authors Affiliation, see end of text.

http://www.banglajol.info/index.php/JBSP

\section{Introduction}

$\mathbf{E}$ nglish is considered to be lingua franca of sciences. Lingua franca means any language that is widely used as a means of communication among speakers of other languages. English has become the second language of everybody. At the current stage of globalization and technology, English dominates the world as no language ever has, and some linguists are now saying it may never be dethroned as the king of languages. ${ }^{1}$ English has

Received 26 March 2017; Accepted 10 May 2017 come out in non-English speaking countries as ESP (English for specific purposes). ${ }^{2}$ As the world continues to become more interconnected, the spread and importance of English on every continent becomes increasingly more pronounced. The link between globalization and English is tangible. English and globalization have spread hand in hand through the world. This process started with the dominance of two successive English-speaking empires, British and American, and continues today with the new virtual empire of the internet. ${ }^{1}$ The most powerful 
aspect of the English language is the speed at which the language has spread the globe. ${ }^{3} \mathrm{By}$ 2050 , it is projected that nearly half of the world's population will be proficient in English. ${ }^{4}$ The power of the English language is seen in the political, economic and educational spheres of the global stage. Politically, English is an official or working language of most international political gatherings throughout the world and $85 \%$ of international organizations use English as the language of official communications. , $^{4,5}$ Economically, the Harvard Business Review calls English 'the global language of business' ${ }^{6}$

Due to educational reason, many nations have in recent years made English an official language in schools. ${ }^{5}$ English language is used as the language of business, technology, science, the Internet, popular entertainment, and even sports. In academic contexts, it was estimated that more than $50 \%$ of the millions of academic papers published each year are written in English, and the percentage was growing year by year. English is currently the undisputed language of science and technology, and scientific journals in many countries are now switching from the vernacular to English. ${ }^{7}$ In specific disciplines, English appears to be the universal language of communication. For example, $98 \%$ of German physicists now claim English as their de facto working language. They are closely followed by chemists (83\%), biologists (81\%), and psychologists $(81 \%){ }^{8.9}$

Within Europe, English is increasingly used as the language of instruction in selected programmes, especially at master's level and those courses attracting students from Asia. ${ }^{10}$ This trend has been motivated by a number of factors, including standardizing degrees across EU countries. Another reason has been the influx and exchange of students for whom English serves as a medium of instruction. ${ }^{11}$ The vast majority of textbooks and other course literature across most disciplines are English-language publications. At the same time, most universities now encourage their faculty to publish in international peer-reviewed journals. ${ }^{12}$ In a bulletin, British Council stated that in many countries the educational infrastructure does not support quality EMI (English as Media of Instruction) provision. There is a shortage of linguistically qualified teachers. There appear to be few organizational or pedagogical guidelines which might lead to effective EMI teaching and learning. ${ }^{13}$ In Bangladesh, medical students has to encounter English as a learning media. But medical teachers usually do not use English exclusively in their lectures thinking that students may not be able to understand, though this notion has not been scientifically tested. So, this study was designed to find out the impact of exclusive English use in physiology lecture on students' learning in Bangladesh .

\section{Methods}

This comparative study was conducted in the Department of Physiology, Abdul Malek Ukil Medical College, Noakhali, Bangladesh, during the period of January, 2013- November, 2013. Permission was taken from concerned authorities. One hundred and sixteen first year MBBS students of two sessions of a selected government medical college of Bangladesh were enrolled for the study by purposive sampling. Exclusive English was used in physiology lectures of $1^{\text {st }}$ term course for the students of 2012-2013 session and were grouped as 'group $\mathrm{EE}$ ' and the same lectures were delivered in mixed language of Bengali and English for the students of 2011-2012 session and were designated as 'group BE'. Data on admission merit-score and first term examination marks were collected in a questionnaire. Data were analyzed by using SPSS version 16. The marks obtained by two groups were compared by unpaired Student's ' $t$ ' test and pass rate was compared by chi-square test. $P$ value $<0.05$ was considered significant. 


\section{Result}

There were $18(31 \%)$ male and 40(69\%) female students in group EE and 30(51.7\%) male and $28(48.3 \%)$ female students in group BE. Female students were significantly more in group $\mathrm{EE}$ than in group $\mathrm{BE}(\mathrm{p}<0.05)($ Table I).

Table I : Comparison of gender between two groups $(n=116)$

\begin{tabular}{lcc}
\hline Gender & $\begin{array}{c}\text { Group EE } \\
(\mathrm{n}=58) \mathrm{f}(\%)\end{array}$ & $\begin{array}{c}\text { Group BE } \\
(\mathrm{n}=58) \mathrm{f}(\%)\end{array}$ \\
\hline Male & $18(31)$ & $30(51.7)^{*}$ \\
Female & $40(69)$ & $28(48.3)^{*}$ \\
\hline
\end{tabular}

$*=\mathrm{p}<0.05 \mathrm{EE}=$ exclusive English $\mathrm{BE}=$ Bengali English mixed

The admission test score of group EE was significantly higher than group BE $(163.48 \pm 1.75$ vs $151.55 \pm 1.52, \mathrm{p}<0.001$ ). (Table II). The students of group EE obtained significantly more mean marks than group BE in written $(51.77 \pm 8.37$ vs $43.41 \pm 3.82, \mathrm{p}<0.001)$ and oral $(70.88 \pm 8.14$ vs $45.91 \pm 4.40, \mathrm{p}<0.001$ ) examinations (Table II).

Table II: Comparison of admission score, written and oral marks between two groups $(n=116)$

\begin{tabular}{lcc}
\hline Parameters & $\begin{array}{c}\text { Group EE } \\
(\mathrm{n}=58)\end{array}$ & $\begin{array}{c}\text { Group BE } \\
(\mathrm{n}=58)\end{array}$ \\
\hline Admission score & $163.48 \pm 1.75$ & $151.55 \pm 1.52^{* * *}$ \\
(Full mark 200) & & \\
Written marks & $51.77 \pm 8.37$ & $43.41 \pm 3.82^{* * *}$ \\
(Full mark 100) & & \\
Oral marks & $70.88 \pm 8.14$ & $45.91 \pm 4.40^{* * *}$ \\
(Full mark 100) & & \\
\hline
\end{tabular}

Data expressed as mean \pm SD $* * *=\mathrm{p}<0.001$

In group EE, 23(39.7\%) students passed, $29(50.0 \%)$ failed and 6(10.3\%) were absent and in group BE, 24(41.4\%) students passed, 27(46.6\%) failed and 7(12.1\%) were absent. However there was no significant difference in pass rate $(p>0,05)$ (Table III).

Table III : Comparison of frequency $\%$ of pass rate between two groups $(n=116)$

\begin{tabular}{ccc}
\hline Gender & $\begin{array}{c}\text { Group EE } \\
(\mathrm{n}=58) \text { No. }(\%)\end{array}$ & $\begin{array}{c}\text { Group BE } \\
(\mathrm{n}=58) \text { No. }(\%)\end{array}$ \\
\hline Passed & $23(39.7)$ & $24(41.4)$ \\
Failed & $29(50.0)$ & $27(46.6)$ \\
Absent & $6(10.3)$ & $7(12.1)$ \\
\hline
\end{tabular}

\section{Discussion}

The English language is the medium of instruction of medical science in Bangladesh. The Physiology text books for medical students are written in English. If students are not taught in English none can expect them to answer efficiently either in written or in oral examinations. The students qualified for the MBBS admission are supposed to have the background knowledge of English that is necessary to understand the script of book or to understand the lecture of the teachers which are supposed to be taken with exclusive English. Sometimes students dare not to speak in English in oral exam when their teachers ask question in Bengali. If mixed language is used the content of the lecture is finished within a short time and non-Bengali speaking students become disappointed which may be cause of loosing dignity towards the teacher.

The design of this study aimed to assess the impact of exclusive English language use in physiology lectures on students' learning ability.

The present study found that the students who attended lectures of exclusive English obtained significantly more marks both in written and oral exam than who attended lectures with mixed Bengali and English. This finding is consistent with the findings of Wong ${ }^{14}$.

J Bangladesh Soc Physiol. 2017, June; 12(1): 28-32 
In his study, Wong found that students are generally in favour of using English exclusively in classroom and their preference is positively related to their own English proficiency. Such exclusive English language policy provided these students with the chance to use English as the sole means of communication, rather than merely conducting an academic exercise. If teachers allow native languages to be used in classrooms, student opportunities to learn English are lessened. In a rather monolingual society, maximising students' chances and exposure to English should be one of the prime responsibilities of a teache He further explained that evidence indicates that students should be exposed to as much English as possible. More importantly, students will become more comfortable in an English-rich communication forum. Study results suggest that students who were strictly required to use English in class were more active in class participation. Exposure to English was also increased because students literally have no other options. However, if students are allowed their choice of English or native language, they will naturally choose their native tongue. In addition, it has now been proven that enforcement of a strict English-only policy with students has a great positive impact on learning. 14

The findings of this study was in line with the finding of Bolton and Maria ${ }^{15}$. They found that in lectures classes, the greatest use of English was found to occur in the science faculty, where $23 \%$ of students reported that either 'about half' or 'all/almost all' of their lectures were given in English. Lower totals were reported for the humanities with 15\%, the Social Sciences with $13 \%$ and law with $6 \% .^{15}$ In contrast, several undergraduate students made additional comments about English medium instruction. Some of them offered a rather negative assessment of taking lectures in English, with reference to their teachers' poor language skills. ${ }^{16}$ The parallel use of English and Swedish, however attractive to policy makers, was sometimes seen as confusing by students. The learning difficulties caused by the language switch are related to subject-specific terminology and code- switching. ${ }^{17}$ In addition, some students indicated that they found it difficult to sit examinations in native language when the course literature was in English. ${ }^{17}$

However our findings are not in agreement with the findings of some investigators ${ }^{18-20}$

Bernardo observed that, the bilingual students generally performed better in mathematics word problems which are written in native language, compared to those in English ${ }^{18}$. This advantage in using native language is related to another finding which showed that the students were more accurate in comprehending the word problem texts when these were written in native language and they also had more comprehension errors when the problems where written in English. ${ }^{19-20}$ Moreover, the weaker performance in English is not simply due to problems of comprehension. The students were also better able to understand and apply conceptual knowledge in mathematics when this was presented in native language. ${ }^{21}$. However, bilingual students seemed to perform better when the mathematical problem solving task was in English. ${ }^{22}$

There were some limitations with respect to the methodology of this study which could potentially might have affected the accuracy of results. First, the 'group EE' and the 'group BE' were not selected from the same session because the researcher did not have the opportunity to divide the students of same academic session into two groups and teach them in two system of language choosing due to lack of teachers and small number of sample size. Second, the two groups of this study were not similar in the term of gender and merit score. Dissimilarities in gender between two groups may not affect the result of the exam because one study showed that there is no difference in physiology result between male and female medical students. ${ }^{23}$ The merit score of two different academic sessions may not be similar inspite two study groups having similar knowledge. Statistically, the two groups could only be measured by pre-tests conducted during the study, but which was not taken. Therefore, the results might have some 
flaws. In addition, there may have other differences contributing to the learning effect. So a study with similar two groups, preferably from the same academic session is recommended to achieve possible true difference between two groups.

\section{Conclusion}

The students who attended the lectures with exclusive English obtained more marks than the students who got the lectures with mixed English and Bengali. However, the success rate was similar in both the groups. So the impact of English on student's physiology learning remained in ambiguity.

\section{Conflict of interest: None}

\section{Acknowledgement}

We are thankful to Mr. Raqiub, AMUMC for providing admission merit score.

\section{Authors' affiliations}

1. Mohammad Uzire Azam Khan,Associate Professor, Department of Physiology, Abdul Malek Ukil Medical College, Noakhali, Bangladesh.Email: uzire@ yahoo.com

2. Mohammad Mohaimenul Abedin, Lecturer, Department of Physiology, Abdul Malek Ukil Medical College, Noakhali, Bangladesh.

\section{References}

1. Mydans S. Across cultures, English is the word. New York Times.2007, April 9.

2. Ghanbari B. ESP Practitioner Professionalization through Apprenticeship of Practice: The Case of Two Iranian ESP practitioners. English Language Teaching. 2010;5(2):112-122.

3. Crystal D. The language revolution. 2004, Malden, MA: Polity Press.

4. The Triumph of English: A world empire by other means. (2011, December 9). The Economist. UNESCO. (2013).available from: www.unesco.org. access on $02 / 02 / 2017$.

5. Crystal D. English as a global language Cambridge: Cambridge University Press; 2003.

6. Neeley, T. Global business speaks English. Harvard Business Review.2012, May.

7. Swales J. Utilizing the literatures in teaching the research paper. TESOL Quarterly. 1987;21:41-68.

8. Graddol D. The future of English. London: British Council.1997
9. Crystal D. English as a global language. Cambridge: Cambridge University Press;1997.

10. Marginson, S., and M. van der Wende. The new global landscape of nations and institutions. In:Higher Education to 2030, Paris: OECD. 2009;2:32-33.

11. Wachter B and Maiworm F. English-taught programmes in European higher education: The picture in 2007. Lemmens: ACA Papers on Cooperation in Education.(2008).

12. Nilsson B. Internationalisation at home from a Swedish perspective: The case of Malmo. J Stud Int Edu 2003;7(1):27-40.

13. Dearden J. British council. English as a medium of instruction- a growing global phenomenon(2014). Available from: http://englishagenda.british council.org. access on 02/02/2017.

14. Wong RM. The effectiveness of using English as the sole medium of instruction in English classes: student responses and improved English proficiency. Porta Linguarum 2010;13: 119-130.

15. Bolton K and Kuteeva M. English as an academic language at a Swedish University: Parallel language use and the 'threat' of English (2012). Available from:http://www3.ntu.edu.sg, access on 02/02/2017.

16. Bjorkman B. Spoken lingua franca English at a Swedish technical university: An investigation of form and communicative effectiveness. Stockholm: Stockholm University (2010).

17. Airey J. Science, language, and literacy: Case studies of learning in Swedish university physics. Uppsala: Uppsala University (2009).

18. Bernardo ABI. Overcoming obstacles to understanding and solving word problems in mathematics. Educational Psychology. 1999; 19:149-163.

19. Bernardo ABI. Language and mathematical problem solving among bilinguals. J Psy 2002;136:283-297.

20. Bernardo ABI and Calleja MO. The effects of stating problems in bilingual students' first and second languages on solving mathematical word problems. J Gen Psy 2005;116:117-128.

21. Reyes ML. Differential effects of mathematical ability and language use on computational and conceptual knowledge of descriptive statistics. The Asia-Pacific Edu Res. 2000;9:83-115.

22. Bernardo ABI. Asymmetric activation of number codes in bilinguals: Further evidence for the encoding-complex model of number processing. Memory \& Cognition.2001;29: 968-976.

23. Khan MUA. Comparison in the Physiology results between male and female undergraduate medical students. J Bangladesh Soc Physiolo 2016;11(2): 47-49.

J Bangladesh Soc Physiol. 2017, June; 12(1): 28-32 